\title{
Proposal for Evaluating a Connection Quality within Transport Networks
}

\author{
Vladimír L'upták ${ }^{1, *}$, Jozef Gašparík ${ }^{2}$, and Mária Chovancová ${ }^{1}$ \\ ${ }^{1}$ Institute of Technology and Business in České Budějovice, Faculty of Technology, Okružní 517/10, \\ 37001 České Budějovice, Czech Republic \\ ${ }^{2}$ University of Žilina, Faculty of Operation and Economics of Transport and Communications \\ Univerzitná 1, 01026 Žilina, Slovakia
}

\begin{abstract}
The paper deals with a proposal of the connection quality evaluation on a particular transport network within passenger transport. Currently, there is no relevant methodology for a comprehensive evaluation of timetables in general and no selected indicators for evaluating the connection quality on a transport network. The aim of the paper is to outline the way to evaluate the timetable in passenger transport in terms of connectivity and connection. From a passenger's perspective, it is necessary to evaluate the availability of opportunities to travel between selected locations on a railway network. The transport offer from the place A to the place B basically affects the transportation time, the number of transfers and the number of travel opportunities. This represents the starting point for designing a set of criteria in order to evaluate the overall connection quality.
\end{abstract}

\section{Introduction}

The offer of connection, assigned by the transport enterprise, depends on the demand for the carriage of passengers who need to move to another location between the two points on a transport network for objective or subjective reasons. Figure 1 shows the areas of quality evaluation as well as their schemes. In terms of connections quality evaluation on a transport network, operational processes and transport processes have an important role, and the paper is focused on them. Supplementary services, awareness and comfort are supportive areas complementing the quality of the transportation process [1-3].

*Corresponding author: luptak@mail.vstecb.cz 


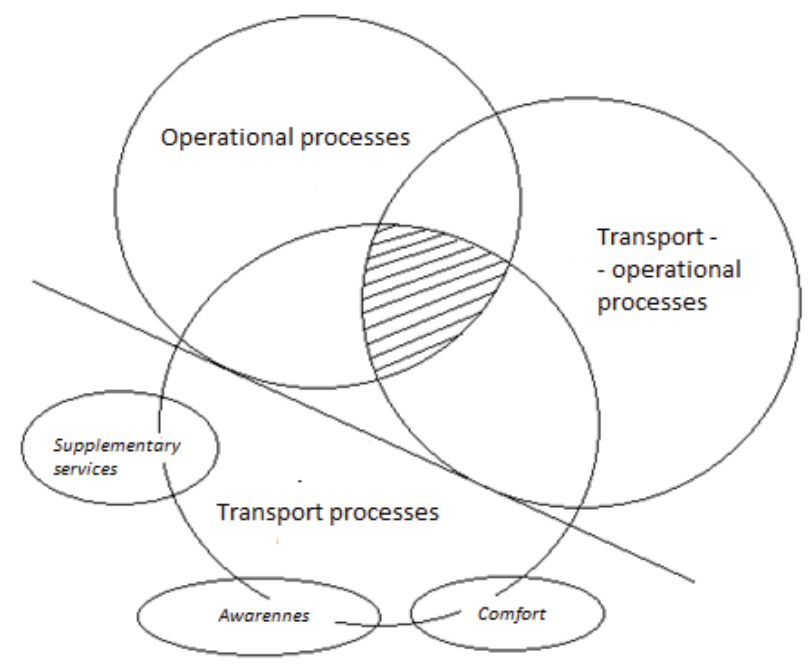

Fig. 1. Coincidence of transport processes with impact on the connection quality on a transport network. Source: [1]

The transport system, its structure and processes depend on the direct and indirect effects of surrounding. The quality of the provided transport services is given by a set of aspects, referred to as quality indicators: regularity, reliability, safety, speed, economy, reasonable cost, ecology, comfort, performance and availability. Quality is a dynamic phenomenon related to a particular object or process over time. Current quality status is a function of real conditions, possibilities and intent in real time, with individual aspects developing in desirable or undesirable ways. This is caused due to the objective necessity of continuous quality management $[1,2,4-6]$.

\section{Proposal of the connection evaluation methodology on a transport network}

The resulting suggestion of the paper is to integrate the synergies and drawings of the qualitative indicators characterizing the connection on a transport network as well as the elements of the connection quality between the tariff points on the transport network. The methodology of connection quality evaluation aims to cover the possibilities of achieving any pair of tariff points on the selected transport network comprehensively [4-7].

The proposed methodology is based on the evaluation of defined criteria for the connection between selected tariff points on a network. The evaluation of a particular connection is the fundamental part of such a methodology. It is necessary to determine whether connections are evaluated during a working day or weekend, or process the evaluation separately for the selected working days, Saturday or Sunday. Consequently, summary indicators are evaluated for connections within a transport relation and within an entire network $[7,8]$.

The new methodology, which includes partial quality evaluations of the connection on a transport network, should offer a comprehensive evaluation defined by successive steps. The interconnection of the individual indicators must allow for an equalized evaluation of the connection in terms of the transportation quality. It means to take into account all the connections on a selected network. The following steps represent a part of the evaluation process: 
1. selection of a transport network,

2. selection of the set of connections,

3. selection of relevant tariff points on a transport network,

4. selection of evaluation indicators,

5. evaluation of individual relations,

6. evaluation of all the connections within the relation,

7. network connection evaluation.

\subsection{Selection of a transport network}

In this step, it is necessary to define a transport network (railway, road, air, water, public transport, etc.). In the next step, a selected transport network will be subject to the quality evaluation itself. This selection can be specified according to the mode of transport, operator and transport network, or other criteria. These may also include the integrated transport system lines. The network is defined by the set of tariff points (vertices of graph) and the set of road transport relations connecting the tariff points (edges of graph) [7,9].

\subsection{Selection of a set of connections}

In the second step, it is necessary to select the connections. This selection may be divided according to the carrier providing transport on the selected network, depending on the mode of transport, or to choose a complete search across all available connections between all the carriers $[8,9]$.

\subsection{Selection of relevant tariff points on a transport network}

In order to comprehensively assess the connection between the tariff points (stations, stops, interchanges) in the timetable, it is necessary to determine suitable quality indicators characterizing the performance indicator of this connection $[1,10,11]$.

\subsection{Selection of evaluation indicators}

The following factors are identified when evaluating the connectivity and connection quality of transport relations [12-18]:

- number of connections $\mathrm{N}_{\mathrm{s}}$,

- average waiting time of the passenger,

- distance of the $\mathrm{L}_{\mathrm{i}}$,

- type of train and number of trains,

- transportation time $\mathrm{T}_{\mathrm{p}}$,

- number of transfers $\mathrm{N}_{\mathrm{pi}}$,

- transfer time $\mathrm{T}_{\mathrm{wi}}$,

- time to reach the destination $\mathrm{T}_{\mathrm{Di}}$,

- speed of transportation $\mathrm{V}_{\mathrm{Pi}}$,

- speed of reaching the destination $\mathrm{V}_{\mathrm{Di}}$.

\subsection{Evaluation of individual relations}

After processing a connection evaluation within one relation, it is necessary to evaluate the given relations between the tariff points in a network. For simplification, the relevant 
selection of tariff points is required. To evaluate a specific connection in a selected relation, a table of all connections must be compiled, as shown in the Table $1[1-3,7]$

Table 1. General table for connections evaluation on a transport relation. Source: $[1-3,7]$

\begin{tabular}{|c|c|c|c|c|c|c|c|c|c|c|c|}
\hline 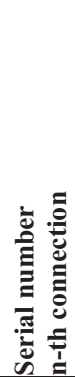 & 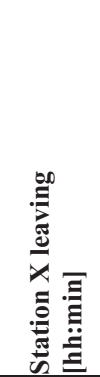 & 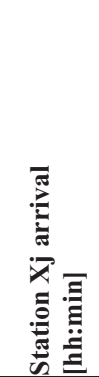 & 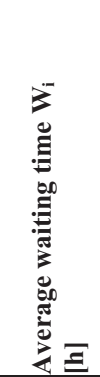 & 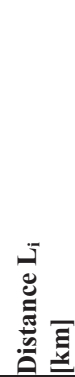 & 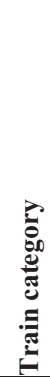 & 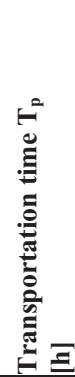 & 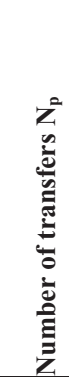 & 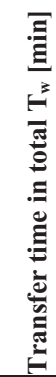 & 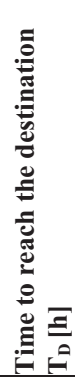 & 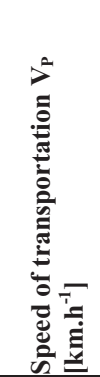 & 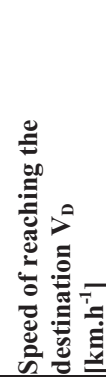 \\
\hline 1 & $\mathrm{~T}_{\mathrm{odXi}}$ & $\mathrm{T}_{\mathrm{prXj}}$ & $\mathrm{W}_{\mathrm{i}}$ & $\overline{L_{i}}$ & & $\mathrm{~T}_{\mathrm{pi}}$ & $\mathrm{N}_{\mathrm{pi}}$ & $\mathrm{T}_{\mathrm{wi}}$ & $\mathrm{T}_{\mathrm{Di}}$ & $V_{\mathrm{Pi}}$ & $V_{D i}$ \\
\hline 2 & & & & & & & & & & & \\
\hline 3 & & & & & & & & & & & \\
\hline . & . & . & & & & & . & & . & . &. \\
\hline & & & & & & & & & & . & \\
\hline & & & & & & & & & & . & \\
\hline & & & & & & & & & & & \\
\hline
\end{tabular}

\subsection{Evaluation of all the connections within the relation}

When evaluating the connection within a relation, the selected indicators are aggregated to the average values, which serves to resulted evaluation of the entire relation This also represents the basis for a comprehensive connection quality evaluation. Table 2 shows the proposed indicators monitored during 24 hours to evaluate the connection quality on a network $[1-3,7]$.

Table 2. General table for the entire relation evaluation. Source: [1-3, 7]

\begin{tabular}{|c|c|c|c|c|c|c|c|c|c|c|c|}
\hline 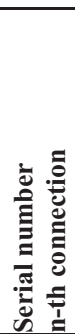 & 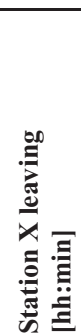 & 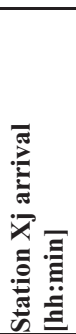 & 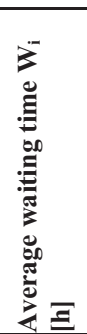 & 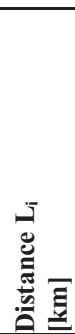 & 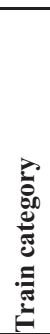 & 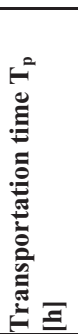 & 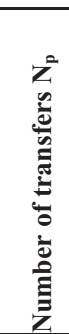 & 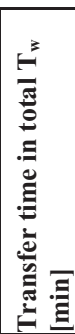 & 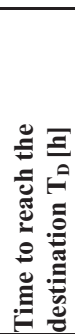 & 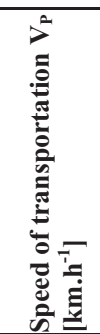 & 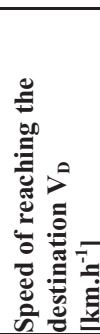 \\
\hline \multicolumn{12}{|l|}{1} \\
\hline \multicolumn{12}{|l|}{2} \\
\hline \multicolumn{12}{|l|}{3} \\
\hline$\dot{\theta}$ & & & & & & & & & & & \\
\hline . & & & & & & & & . & & & \\
\hline . & & & & & & & & . & & & \\
\hline $\mathrm{n}$ & & & & & & & & & & & \\
\hline & Averas & ies & $\overline{n e c}$ & in & & & $\varnothing \mathrm{N}_{\mathrm{p}}$ & $\varnothing T_{w}$ & $\varnothing \mathrm{T}_{\mathrm{d}}$ & $\varnothing \mathrm{V}_{\mathrm{P}}$ & $\varnothing \mathrm{V}_{\mathrm{D}}$ \\
\hline
\end{tabular}

\subsection{Network connection evaluation}

In the last step, it is necessary to summarize the partial average values of monitored indicators on relations to the matrix table, as shown in Table 3. All the evaluated relations on a network can be evaluated in accordance with the monitored indicators or the weighted 
arithmetic mean of amount of passengers, thus the quality of the connection or the compiled timetable on a selected transport network is assessed [1-3, 14].

Table 3. General table for the connection quality evaluation on a transport network. Source: $[1-3,14]$

\begin{tabular}{|c|c|c|c|c|c|c|c|}
\hline $\begin{array}{l}\text { Monitored quality indicator of the } \\
\text { connection on a transport network }\end{array}$ & 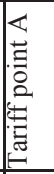 & 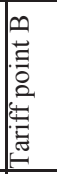 & 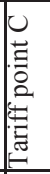 & . & 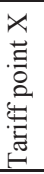 & & 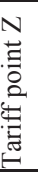 \\
\hline Tariff point $\mathrm{A}$ & & & & 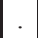 & & & \\
\hline Tariff point B & & & & $\cdot$ & & & \\
\hline Tariff point $\mathrm{C}$ & & & & $e^{\prime}$ & & & \\
\hline$\cdots$ & $\ldots$ & $\ldots$ & $\ldots$ & $\cdot$ & $\ldots$ & $\ldots$ & $\ldots$ \\
\hline Tariff point $\mathrm{X}$ & & & & . & & & \\
\hline Tariff point $Y$ & & & & . & & & \\
\hline Tariff point $Z$ & & & & . & & & \\
\hline
\end{tabular}

After identifying all the average monitored indicators, the average number of transfers over an entire transport network can be calculated. When evaluating the transport quality on a transport network, many aspects can be taken into consideration, such as [16, 19-22]:

a) based on the arithmetic average

- the average number of transfers,

- average time to reach,

- average speed of transportation,

b) average speed of reaching the destination using a weighted arithmetic mean of the number of passengers.

\section{Conclusion}

For the field of evaluating the connection quality on a transport network, a number of standards, regulations and directives are implemented in national law and legislation. However, each passenger or potential passenger perceives the quality of connection and accessibility in a subjective way. Currently, emphasis is placed on ensuring the quality of the transport process focusing on means of transport, stations and stops. In order to objectify the quality of the connection in any transport system, it is necessary to comply with these standards, however for the connection quality evaluation from the transport point of view, it is necessary to develop a uniform methodology. Until now, such an uniform methodology has not been designed in the Slovak Republic or EU. For example, different timetables are drawn up every year in railway transport conditions and have led to controversy about the availability quality of different tariff points on the network. 
The above-mentioned ideas and the fundamentals of the connection quality evaluation support the promotion of the EU transport policy objectives in the field of transport, i.e. promoting the mobility of the population by environmentally friendly modes of transport. These objectives are expressed particularly in the White Paper - Single European Transport Area, where at the national level, the Slovak Republic expresses its opinion through the transport policy of the Slovak Republic, the Transport Development Strategy of the Slovak Republic up to 2020, the Strategic Plan for Development of Transport Infrastructure of the Slovak Republic by 2020, Strategies for the development of public passenger and nonmotor transport by the SR by 2020 and several other documents approved by the Slovak Government.

The methodology outlined in the paper fully covers the possibility of achieving any pair of tariff points on a selected transport network. The methodology offers not only a connections evaluation within the selected relation, but also an objective evaluation of the connections availability between two selected tariff points based on qualitative indicators such as average number of transfers, average waiting time, average transfer rate and average speed of reaching the destination. It evaluates the quality of the provided passenger travel opportunities in the selected territory by selected indicators.

This paper is supported by the research project "From horse-drawn railway to intermodal transport" within Visegrad Fund.

\section{References}

1. J. Gasparik, O Stopka, L. Peceny, Nase more 62, 3, 114-118 (2015), DOI: 10.17818/NM/2015/SI5

2. L. Bartuška, L. Černá, J. Daniš, Naše more 63, 3, 93-97 (2016), DOI: $10.17818 / \mathrm{NM} / 2016 / \mathrm{SI} 3$

3. O. Stopka, I. Šimková, V. Konečný, Naše more 62, Special Issue, 126-130 (2015), DOI: $10.17818 / \mathrm{NM} / 2015 / \mathrm{SI} 7$

4. L. Černá, V. Zitrický, J. Ponický, MME - 34th international conference Mathematical methods in economics, 126-131 (Liberec, Czech Republic, 2016)

5. Y.G. Zhang, Q. Y. Liu, D.Y. Lei, X.P. Xu, J.Z. Zhao, Joint 2016 - ICEME 2016 International Conference on Economics and Management Engineering and EBM 2016 - International Conference on Economics and Business Management, 481-486 (China, 2016)

6. T.J. Mlinaric, T. Plesa, I. Balagic, CETRA - 2nd International Conference on Road and Rail Infrastructure, 875-880 (Dubrovnik, Croatia, 2012)

7. B. Gorlewski, Logi - Scientific Journal on Transport and Logistics 2, 1, 16-26 (2011)

8. N. Aydin, Transport Policy 55, 87-98 (2017), DOI: 10.1016/j.tranpol.2017.02.001

9. B. Abramovic, V. Zitricky, P. Mesko, Logi - Scientific Journal on Transport and Logistics 8, 1, 1-10 (2017), DOI: 10.1515/logi-2017-0001

10. Z. Bryniarska, L. Zakowska, CSUM 2016 - 3rd Conference on Sustainable Urban Mobility, 25-32 (Transportation Research Procedia 24, 2017), DOI: $10.1016 /$ j.trpro.2017.05.063

11. E. Semchugova, V. Zyryanov, N. Negrov, A. Nikitina, SPBOTSIC-2016 - 12th international Conference - Organization and Traffic safety Management in Large 
Cities, 584-590 (Transportation Research Procedia 20, 2017), DOI: $10.1016 /$ j.trpro.2017.01.094

12. C. Oprea, E. Rosca, M. Popa, A. Ilie, O. Dinu, M. Rosca, IMANEE 2016 - 20th Innovative Manufacturing Engineering and Energy Conference, UNSP 012098 (IOP Conference Series-Materials Science and Engineering 161, 2016), DOI: 10.1088/1757$899 \mathrm{X} / 161 / 1 / 012098$

13. V.I. Sopov, V.V. Biryukov, 9th Russian/Korean International Symposium on Science and Technology - Book Group Authors, 396-399 (Novosibirsk, Russia, 2005), DOI: 10.1109/KORUS.2005.1507741

14. C. Hokstok, Logi - Scientific Journal on Transport and Logistics 4, 1, 63-80 (2013)

15. A.O. Baba, O. Bamaarouf, A. Rachadi, H. Ez-Zahraouy, International Journal of Modern Physics C 28, 5, 1750064 (2017), DOI: 10.1142/S0129183117500644

16. J. Ližbetin, L. Černá, M. Loch, Nase More 62, 3, 147-152 (2015), DOI: 10.17818/NM/2015/SI11.

17. D.U. Kim, J.D. Ryoo, J.H. Lee, B.C. Kim, J.Y. Lee, Etri Journal 38, 1, 18-29 (2016), DOI: 10.4218/etrij.16.0115.0024

18. S. Kudlac, J. Majercak, C. Mankowski, 12th International Scientific Conference of Young Scientists on Sustainable, Modern and safe Transport, 510-515 (Procedia Engineering 192, 2017), DOI: 10.1016/j.proeng.2017.06.088

19. R. Kampf, O. Stopka, I. Kubasakova, V. Zitricky, WMCAUS 2016 - World Multidisciplinary Civil Engineering-Architecture-Urban Planning Symposium, 15381544 (Procedia Engineering 161, 2016), DOI: 10.1016/j.proeng.2016.08.623

20. J.G. Dias, G. Trindade, Social Indicators Research 129, 3, 1383-1399 (2016), DOI: $10.1007 / \mathrm{s} 11205-015-1168-2$

21. M. Weiszer, G. Fedorko, V. Molnar, CLC 2013 - Carpathian Logistics Congress, 330335 (Krakow, Poland, 2014)

22. L. Guihery, Research in Transportation Economics 48, 298-304 (2014), DOI: $10.1016 /$ j.retrec.2014.09.056 